\title{
INCERTIDUMBRE Y MALESTAR SUBJETIVO EN CHILE: UNA RADIOGRAFÍA A LA INSEGURIDAD HUMANA COMO FENÓMENO MULTIDIMENSIONAL
}

\author{
Rodríguez Garcés, Carlos \\ carlosro@ubiobio.cl \\ https://orcid.org/0000-0002-9346-0780 \\ Geraldo Padilla Fuentes \\ gpadilla@ubiobio.cl \\ https://orcid.org/0000-0003-0882-1818 \\ Javier Ávila Bascuñán \\ javier.avila1501@alumnos.ubiobio.cl \\ https://orcid.org/0000-0002-6921-2808 \\ Universidad del Bío-Bío \\ Centro de Investigación CIDCIE, Chillán, Chile
}

Recibido: 2020-03-22; Aceptado: 2020-11-15

\section{Resumen}

La inseguridad de la ciudadanía va más allá de lo delictivo, abarcando múltiples dimensiones de la vida social contemporánea; la raíz compartida es la incertidumbre, el sentirse vulnerable. Bajo tal premisa, este artículo analiza la situación de inseguridad ciudadana desde un enfoque multidimensional, enfatizando la perspectiva humana del riesgo percibido. Para esto se utilizan los datos de la encuesta de Bienestar Subjetivo aplicada por el PNUD en Chile el año 2011. Entre los resultados destacan tres hallazgos. Primero, la sensación de vulnerabilidad se encuentra ampliamente extendida entre personas y dimensiones; segundo, los Ingresos, la Salud, y la Delincuencia se posicionan con notabilidad las productoras de inseguridad, y en menor medida el Trabajo y la Educación. Las conclusiones apuntan en dos direcciones aparentemente contradictorias, y es que, por una parte, pese a los intentos por mitigar su extensión, la inseguridad se ha masificado entre públicos y, por otra, si bien las problemáticas responsables de la incertidumbre son inherentes al colectivo, los ciudadanos asumen sus consecuencias individualmente.

Palabras clave: Bienestar subjetivo, Salud, Educación, Inseguridad ciudadana, Perspectiva multidimensional.

\section{UNCERTAINTY AND SUBJECTIVE DISCOMFORT IN CHILE: RADIOGRAPHY TO THE HUMAN INSECURITY AS A MULTIDIMENSIONAL PHENOMENON}

\begin{abstract}
The insecurity of citizenship goes beyond crime, covering multiple dimensions of social life; the common root is uncertainty, the feeling of vulnerability. In this sense, this article analyzes the situation of citizen insecurity from a multidimensional approach, reviewing the human perspective of perceived risk. The data from the Subjective Wellbeing survey applied by UNDP in Chile in 2011. The results include two findings. First, the feeling of vulnerability is widespread among people and dimensions; second, Income, Health and Crime are positioned
\end{abstract}


notably as producers of insecurity, and to a lesser extent, Work and Education. The conclusions go in two seemingly contradictory directions; on the one hand, despite attempts to mitigate its extension, insecurity has become widespread among audiences; on the other, although the issues responsible for uncertainty are inherent in the collective, citizens assume their consequences individually.

Key Words: Subjective well-being, Health, Education, citizen insecurity, Multidimensional perspective.

\section{Introducción}

El tránsito de las sociedades hacia periodos post-industriales exige que tanto organizaciones como ciudadanos acepten los términos y condiciones de un contrato social aglomerante e interconectado con el resto del mundo. La transición hacia contextos globales conlleva implícitamente a la adopción de perspectivas tangenciales y maleables en la comprensión acerca de cómo realizar los proyectos de desarrollo, tanto para los grupos nacionales como para los ciudadanos que se reposicionan o crecen en ellos. Apropiarse de la virtualidad que interviene los sectores locales a raíz de la influencia de fenómenos foráneos redefinió lo que antes parecía claro y seguro, haciendo de lo nacional-local-personal algo expuesto (Giddens, 1993; Castells, 2001).

Esta perspectiva de análisis social fue ampliamente discutida durante los 80' y 90’ por pensadores occidentales, como son ejemplo Giddens (1993), Esposito y Nancy (2003) o Beck (2005), cada uno de los cuales buscó dar cuenta de cómo la ampliación de los horizontes de la experiencia social a causa de la globalización y sus dispositivos modernos había exacerbado el cuidado por las fronteras, el temor al extranjero y la inclusión del riesgo al abanico común de sentimientos ciudadanos. Todo un campo de análisis que pretendía explicar la mezcolanza entre contextos locales y extranjeros, sensibilidades endémicas y riesgos sin fronteras, peligros lejanos, pero jamás inofensivos. Si bien la comunicación entre sociedades no es una cuestión exclusivamente moderna, si lo son los aparatos, velocidad e intereses con que los que lo hace actualmente, más aún, la conciencia de las personas acerca de que aquello está sucediendo.

Los medios de comunicación y su instantaneidad, accesibilidad y vigilancia del estado del mundo desembocaron prontamente en la exposición de la pobreza, las enfermedades, la falta de educación y la delincuencia como eventos comunes. Por supuesto que el contexto de esta afirmación es netamente moderno, incluso cercano a lo que autores como Vattimo (2004) han definido más allá de lo moderno (que no se confunda con posmodernidad), por cuanto las funciones, fijaciones y ejes descritos de los medios comunicación responden a un momento 
particular de su historia, al momento de la interconexión, de la preocupación ciudadana por lo males que persisten en el mundo, por la desgracia que puede llegar a suceder o que ya se encuentra en ciernes alrededor suyo. Esta premisa es necesaria de explicitar toda vez que, si una vez abierta la comunicación, las fronteras y la conciencia hacia el afuera el peligro les siguió, los periódicos, la radio, la televisión e internet se han convertido en dispositivos ávidos de este tipo de contenidos.

Las sociedades interconectadas rápidamente iniciaron relaciones no tan solo comerciales y diplomáticas, sino también las preocupaciones ubicuas del riesgo y peligro que significaba la existencia misma (Beck, 2005). A medianías del siglo XX, la experiencia de las guerras y otros conflictos bélicos había dejado en claro la capacidad de conexión entre sociedades, sobre todo, los efectos colaterales, ya sean económicos, políticos o sociales, que puede tener algún evento en el resto del mundo.

Como resultado de lo anterior, la vida cotidiana parece cada vez más flexible, con proyectos a corto plazo y siempre sujeta a externalidades. No solo intervienen en ella características propias del territorio donde se despliega, como por ejemplo las condiciones geográficas, medioambientales o comunitarias inmediatas, sino que también está cruzada por factores externos difíciles de predecir, como desempleo, delincuencia, pobreza, inestabilidad política e incluso terrorismo (Gilbert, 2010). Al interior de sociedades donde todo parece diluirse con prontitud (Bauman, 2015), la vida se ha vuelto un tránsito peligroso por las calles y plazas de ciudades que se distancian del hogar, que asemejan atrios donde el mundo depositaría más riesgos que beneficios (Wallerstein, 2005; Polomer, 2005).

El sentimiento de inseguridad y consiguiente demanda por ser vigilados incrementa su adhesión entre las ciudadanías, sin importar que ello sea a costa de establecer la peligrosidad, la mera virtualidad o sospecha de riesgo, como criterio suficiente para la intervención de los mecanismos de control y corrección (Foucault, 2008). Los contextos que se inauguraron con la globalización y maduración de la modernidad se saturaron de renovados discursos acerca del riesgo, las amenazas y el juego azaroso de las afueras, es decir, no saber cuándo el exterior y sus fluctuaciones apoyan o amenazan la seguridad.

\section{La (in)seguridad ciudadana en Chile}

Durante la década de los 80 '- 90', Chile se presentaba como una potencia emergente capaz de lograr cualquier reto en la búsqueda por mantener lo que varios economistas de la 
época llamaron el milagro chileno, que consistía en el repunte del Producto Interno Bruto a causa de la política económica de shock de corriente liberal que acompaño el plan económico militar de aquel entonces. El espléndido jaguar de Latinoamérica (apodo mediático de Chile), conectado al mercado global y sus transacciones, fue perdiendo fuerza a medida que avanzaban los periodos de crisis en el continente, especialmente por su dependencia a la inversión extranjeros.

Pese a que el país se ubicaba entre los líderes de la región latinoamericana y organizaciones como el Banco Mundial y el Fondo Monetario Internacional elogiaban su proyección, parte importante de la población declaraba sentirse desconectada del acontecimiento, poco involucrada y vulnerable (PNUD, 1998). Las medidas políticas y sociales aplicadas no germinaron tan solo en bonanza, sino también incertidumbre, inseguridad y malestar; la liberalización de los servicios vinculados a derechos fue tal que incluso liberaron la seguridad que la ciudadanía podía tener de acceder a ellos oportuna y gratuitamente.

Como dieron cuenta algunos análisis de aquellos años, el temor que aquejaba las percepciones y seguridades sociales no era endémico, no remitía exclusivamente a la situación política y de seguridad nacional (PNUD, 1998). La misma apertura que había puesto al país en la escena internacional tuvo un efecto inesperado: introdujo en la conciencia y sensibilidad ciudadanos el riesgo como constante, frecuente, tal vez imperceptible pero no por ello ausente.

La situación local paulatinamente fue envuelta por acontecimientos internacionales, por la preocupación hacia la fluctuación de la bolsa, los conflictos entre países geográficamente lejanos, pero mediáticamente cercanos y otros eventos que, aun cuando no tenían un efecto directo sobre las personas, por diversas razones llegaron a sentirse contiguos (Dammert, 2005). Sin dudas, parte importante de esta germinación de incertidumbre la debemos a la irrupción de los televisores en cada hogar, a través de los cuales la conectividad alcanzó sensibilidades cada vez más capilares (Larraín, 2005).

A este panorama de incertidumbre se suma la influencia que tuvo entre la ciudadanía la propaganda del miedo, llevada a cabo fuertemente durante los años 80' a raíz de los plebiscitos que decidirían la continuación o deposición del régimen militar. Aunque la pugna entre sectores políticos y ciudadanos no escatimó en estrategias para dar cuenta de la situación del país, ya fuera como grave o exitosa, lo cierto es que el temor e inseguridad fueron herramientas recurrentes al momento de decidir cómo enfrentar al público. 
Instaurar el orden, resguardar la moral pública y capturar a los delincuentes, fueron objetivos a cumplir bajo cualquier medio para quienes se presentaban como veladores del proyecto nacional (Pratt, 2000), lo cual significó señalar criminalmente a cualquiera que diera señales comunistas o atentara contra el bien público. Una de los rasgos a destacar en toda esta propaganda fue la divulgación de la idea que cualquiera podía ser víctima del mal que acechaba el país, que nadie estaba seguro excepto bajo la guarda militar; cualquiera podía sufrir cualquier cosa en cualquier lugar, premisa más ideológica que policial, tan exitosa que fue acogida por el marco de interpretación ciudadano incluso una vez retornada la democracia (Moulian, 1997).

Entre la geografía criminal que apareció post dictadura, los llamados Delitos de Mayor Connotación Social (DMCS) se han fijado con fuerza en las parrillas mediáticas y discursos políticos, tanto así que constituyen un punto visiblemente trabajado en tiempo de elecciones. Como explican desde Fundación Paz Ciudadana (2015), los DMCS aúnan dos tipologías de crimen: delitos violentos (robo con violencia, intimidación o lesiones; homicidio; violación) y delitos contra la propiedad (robo de vehículo, objeto desde vehículo, en lugar habitado y hurto). Este tipo de actividades constituyen las causas más frecuentes de procesamiento y reclusión de personas en Chile, las que además suelen acompañarse por la repulsa hacia el joven delincuente, tipología de "otro" que se aprecia riesgosa y hacia la cual se demanda corrección por parte de las instituciones de control (Foucault, 2014).

Asumir que la interconexión entre sociedades solamente supone beneficios, ya sean económicos y/o culturales, es una postura inocente, lo mismo pensar que solo acarrea externalidades vinculadas a la inseguridad y el temor. Sin embargo, se producen fenómenos de inseguridad ciudadana que son exacerbados por el sentimiento general de que todo está cambiando todo el tiempo; los proyectos de vida parecen haberse reducido a campos de decisión no más allá del corto-mediano plazo. Por sobre todo, aun cuando la percepción de estar expuesto a la delincuencia ha ganado espacio en las representaciones ciudadanas del otro y el territorio que habita, las cifras que operacionalizan la incidencia de victimización decrecen gradualmente (Díaz y Ortiz, 2014).

\section{La (in)seguridad como fenómeno multidimensional}

Como era de esperar, la vida cotidiana ha cedido parte de su certidumbre al asedio del temor y sus dispositivos de diseminación, con una lánguida capacidad de respuesta o eficacia en la instalación de filtros para mantener íntegra la seguridad subjetiva. Aun cuando el retorno 
a la democracia impregnó en la ciudadanía renovados ánimos acerca del progreso, el trabajo conjunto y la confianza en los otros (PNUD, 1998; 2017a), el éxtasis fue fugaz. Parte significativa de los ajustes que el régimen autoritario aplicó a la responsabilidad estatal en materia de servicios sociales fueron conservados para el funcionamiento del pacto democrático en Chile, lo que a corto plazo constituyó seguir impulsando un modelo de ciudadano anclado al individualismo, la autorresponsabilidad y el autoabastecimiento.

Recluido en su soledad, la figura del ciudadano debe afrontar individualmente un sentimiento de vulnerabilidad transversal que se expande más allá temor a ser víctima de la delincuencia. El trabajo, la salud, la educación y la vejez parecen campos cada vez más afectados por la contingencia; cada decisión a tomar en ellos tiene que vérselas con la interrelación y colateralidad que presentan (Carrión, 2005; Paez, Peón y Ramírez, 2018). Así que el temor por perder el empleo sea causa común de estrés y preocupación entre las personas, situación que deteriora no tan solo la predisposición y satisfacción laboral, sino también la forma en que se relacionan con el entorno familiar, los amigos y colegas (Sora, Caballer y Peiró, 2014); más aún, entre personas mayores el malestar puede incrementar, por cuanto la falta de dinero y carencia en algunas atención médicas tiene consecuencias no tan solo subjetivas, sino también sobre el estado de su salud (Garay y Montes de Oca, 2011).

Es así como muchas personas temen al desempleo pese a disponer de contrato formal y seguro de cesantía; se perciben desamparados frente a la enfermedad y la posibilidad de recibir atención oportuna, de calidad y a costos asequible aun cuando se encuentren suscritos a programas de protección sanitaria; y se proyectan expuestos a la pobreza e insuficiencia de ingresos en la vejez pese a haber cotizado durante toda su vida laboral.

En síntesis, el estudio de la inseguridad se encuentra en un nuevo campo de análisis, cruzada por las dimensiones de la vida moderna (trabajo, educación, salud, vivienda), las externalidades de la urbanización (delincuencia) y las tendencias de la mass media (violencia y consumo). Por ello, este artículo analiza la situación de inseguridad ciudadana desde un enfoque multidimensional, enfatizando el contexto moderno que envuelve el riesgo percibido. Para esto se utilizan los datos de la encuesta de Bienestar Subjetivo aplicada por el PNUD en Chile el año 2011, instrumento inédito que aborda la incertidumbre y el malestar subjetivo como ejes clave de la vida social en Chile. 


\section{Metodología}

\section{Instrumento}

Los datos aquí utilizados corresponden a la encuesta de opinión pública que realizó el Programa de las Naciones Unidas para el Desarrollo (PNUD) durante el mes de septiembre del año 2011 en Chile, la cual explora en la subjetividad de los ciudadanos, sus experiencias y evaluación que hacen de la vida que llevan y el contexto social en que se desenvuelven.

Con el objetivo de captar la complejidad y ambivalencia que chilenos y chilenas comparten en las diferentes dimensiones que componen la vida social, sus logros, temores, aspiraciones y sueños (PNUD, 2012), este instrumento de aplicación cara a cara consulta sobre satisfacción y bienestar en áreas comunes del desarrollo social y humano, entre las que destacan Trabajo, Vivienda, Salud, Educación, Ingresos y Delincuencia. Dimensiones temáticas que son abordadas mediante una batería de ítems en formato Likert con respuesta graduada.

\section{Muestra}

El marco muestral comprende a la población de 18 años y más residente en áreas urbanas y rurales de las 15 regiones del país, lo que corresponde a 2.535 personas. Selección realizada mediante muestreo estratificado por conglomerados en tres niveles (macro zona>región>zona). El error muestral alcanza un 1,9\% considerando un nivel de confianza del $95 \%$.

En términos descriptivos, existe una predominancia de personas residentes en sectores urbanos y de estratos económicos bajos, mientras que el género y etapa de ciclo vital manifiestan una representación homogénea (Tabla 1).

Tabla 1: Caracterización de la muestra (\%)

\begin{tabular}{llll} 
Zona & \multicolumn{2}{l}{ Género } \\
- Urbano & 87,9 & - Hombre & 49,4 \\
- Rural & 12,1 & - Mujer & 50,6 \\
\hline NSE & \multicolumn{3}{c}{ Rango etario } \\
- ABC1 & 8,1 & - 18 y 29 años & 20,8 \\
- C2 & 12,0 & - 30 y 45 años & 28,9 \\
- C3 & 33,1 & - 46 y 60 años & 26,3 \\
- D & 26,8 & - Más de 60 años & 24,0 \\
- E & 20,1 & & \\
\hline
\end{tabular}

Elaboración propia con base en los datos PNUD sobre Bienestar Subjetivo en Chile (2012). 


\section{Procedimiento}

Para exponer la inseguridad como un fenómeno que inunda la vida social de los sujetos, la estrategia de análisis está divida en 3 partes. En primer lugar, se explora el comportamiento de la Inseguridad Humana, índice propio que es producto de la estandarización de 25 ítems, los que a su vez componen las 6 dimensiones objeto de estudio (Trabajo, Educación, Salud, Ingresos, Vivienda y Delincuencia). Esta variable representa la intensidad de la vulnerabilidad percibida por los ciudadanos en su nivel más grueso, para la cual considera las categorías de respuesta negativa en cada batería de preguntas. Para hacer ilustrativas las diferencias, se cruza con el nivel socioeconómico de la población, característica que según la literatura proyecta mejor la situación de las sociedades actuales basadas en el prestigio, la clase y el estatus (Gilbert, 2010; Bourdieu, 2016).

En segundo lugar, las puntuaciones de Inseguridad Humana son desglosadas según dimensiones, conservando la agrupación por nivel socioeconómico. Esta táctica pretende dar cuenta de las diferenciadas preocupaciones que comparte la ciudadanía dependiendo de su situación económica, donde las herramientas y medios de protección frente al temor varían considerablemente según la disponibilidad de recursos para transar en un mercado cada vez más amplio en sus dispositivos y promesas de aislamiento (Bauman, 2015).

En tercer lugar, se presenta el comportamiento de cada una de las dimensiones de la Inseguridad Humana y los ítems que las conforman, acompañadas por breves pero precisos comentarios acerca de las manifestaciones, efectos y formas que la incertidumbre cobra entre los encuestados con base al componente analizado. De esta forma se proyecta la Inseguridad Humana como una estructura multidimensional, entendida como la percepción de vulnerabilidad, incertidumbre y malestar que la ciudadanía tiene en las diversas esferas de la vida cotidiana.

\section{Resultados}

La calidad de vida y el bienestar de territorios y personas no es expresión únicamente de una dimensión objetiva referida a la disponibilidad de bienes y servicios para cada quien, constructo cuyos componentes son tradicionalmente medidos y calibrados por la óptica económica y encuestas del desarrollo social; sino que también considera una dimensión subjetiva, que refiere a la valoración que se hace de la disponibilidad, calidad y oportunidad de aquellos bienes y servicios en relación a la propia vida (Cuadra y Florenzano, 2003; Moyano y 
Ramos, 2007). En pocas palabras, es posible diferenciar el bienestar objetivo y el subjetivo entendiendo al primero como la existencia de elementos que estructuran las condiciones de vida del individuo, y el segundo como resultado de la satisfacción que producen (PNUD, 2012).

Si bien por cultura general y tratamiento mediático la seguridad de la ciudadanía tiende a relacionarse con el resguardo frente al crimen y la posibilidad de ser víctima de algún delito, estos indicadores solamente aluden a una parte de un fenómeno social más complejo (Schwartz, 2001). Por ende, una mirada más amplia debe considerar la importancia que tiene para la comunidad contar, como ejemplo, con estables fuentes de ingreso, vivir bajo techo, gozar de salud y residir en ambientes libres de violencia para definir su estado de conformidad.

En razón de lo anterior, podría definirse la sensación de inseguridad como un continuo en el estado de carencia para consumar satisfactoriamente las necesidades humanas contemporáneas, y que en mayor o menor medida atraviesa todo el espectro de lo social con sus aristas. En efecto, el sentimiento de constante incertidumbre dista de ser patrimonio de las capas sociales más desfavorecidas (Gráfico 1), pues se manifiesta también en quienes teóricamente cuentan con las herramientas y redes para contenerlo, mitigarlo o sortearlo. Aun siendo sensación generalizada, su intensidad, recurrencia y prevalencia multidimensional recibe el impacto directo del grupo social de referencia, de manera que conforme se deteriora el perfil socioeconómico aumenta significativamente la sensación de vulnerabilidad $\left[\mathrm{F}_{(4)}=156,56 ; \mathrm{p}=\right.$ $0,000]$. 
Gráfico 1: índice de Inseguridad Humana según Nivel Socioeconómico

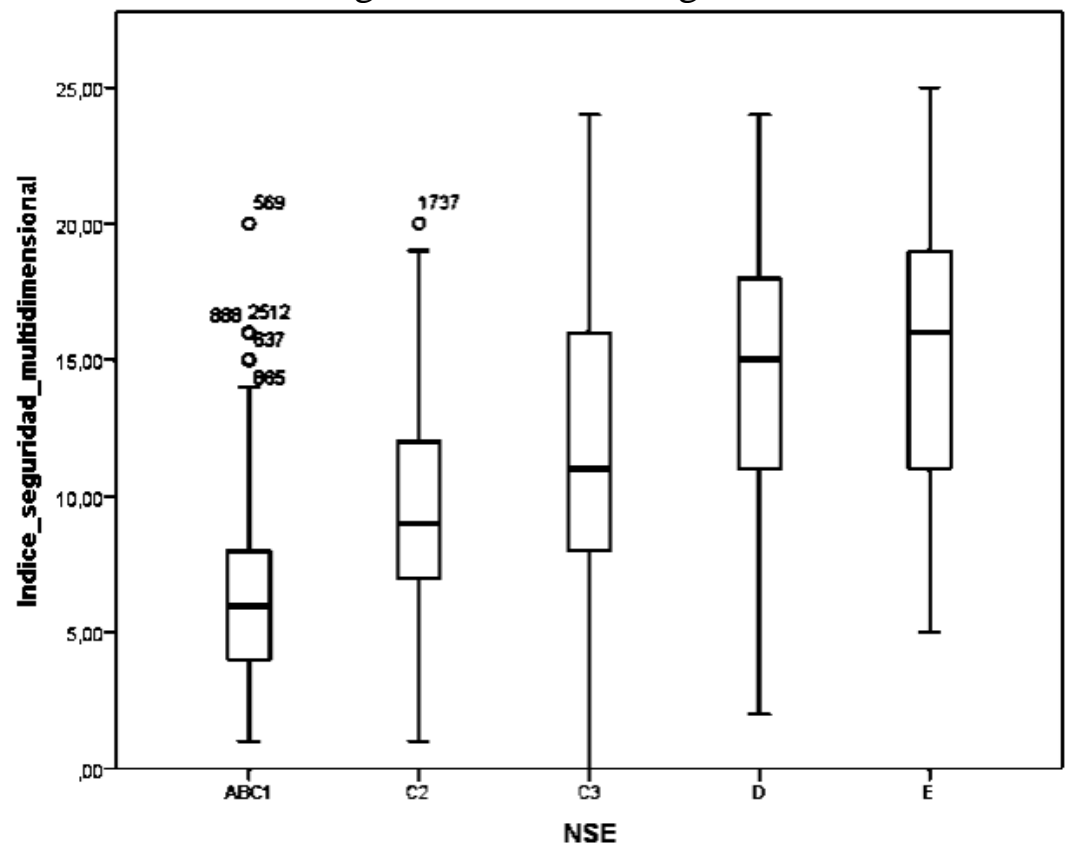

Elaboración propia con base en los datos PNUD sobre Bienestar Subjetivo en Chile (2012).

El déficit de capitales educativos de calidad, el truncado abanico de oportunidades, las precarias condiciones laborales, las menores expectativas salariales y la residencia en barrios de convivencia conflictuada acentúan el sentimiento de inseguridad en las capas socioeconómicas más bajas, donde el carácter estructural de este complejo entramado de carencias no tan solo se profundiza, sino que también se perpetúa al reproducirse a sí mismo.

Gráfico 2: Percepción de Inseguridad Humana según Nivel Socioeconómico
Salud

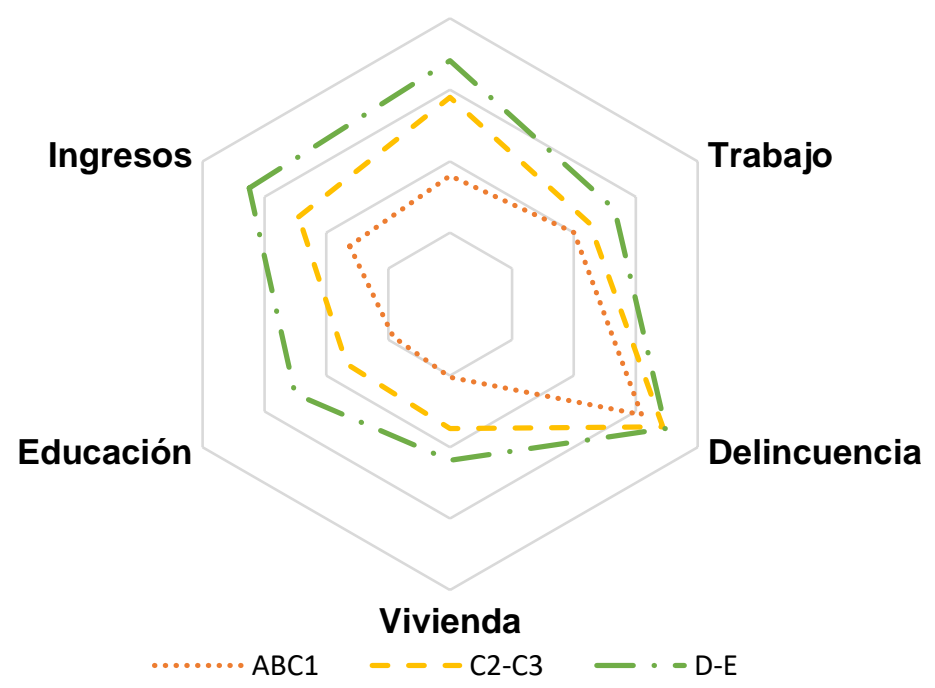

Elaboración propia con base en los datos PNUD sobre Bienestar Subjetivo en Chile (2012). 
Al respecto, el Gráfico 2 reporta la percepción de Inseguridad Humana según nivel socioeconómico, desagregada por dimensión. El miedo a la delincuencia y la pérdida de control ciudadano destacan por sus elevados índices de malestar subjetivo en la generalidad de la población. Otras dimensiones como Salud e Ingresos comportan mayor nivel de preocupación principalmente para los grupos de menores rentas, contrastándose significativas brechas respecto del segmento $\mathrm{ABC} 1$, tanto para salud $[\mathrm{X} 2(16)=496,615 ; \mathrm{p}=0,000]$ como ingresos $[\mathrm{X} 2(24)=537,879 ; \mathrm{p}=0,000]$. En términos generales, las dimensiones de Educación y Vivienda son las que reportan menor sensación de inseguridad, aunque sus valoraciones están igualmente influenciadas por la pertenencia de clase, en especial el componente educativo [X2(12)= 502,919; $\mathrm{p}=0,000]$.

Al refinar el abordaje analítico de las dimensiones, se observa que la inseguridad humana está fuertemente estructurada con base a la percepción del estado de la delincuencia. No obstante el descenso que registran los delitos de mayor connotación social, tales como robos, asaltos y hurtos, la población chilena declara sentirse más vulnerable que antes respecto de la posibilidad de ser víctima (Fundación Paz Ciudadana, 2015). El temor al delito se constituye en lugar común dentro de la opinión pública, siendo valorado como la mayor preocupación ciudadana (CEP, 2015), y es la dimensión que más destaca en el análisis de la Inseguridad como sentimiento ubicuo y socialmente transversalizado (Browne y Valenzuela, 2016). Las cifras alcanzan niveles preocupantes dentro de esta dimensión, donde un 70,2\% de los ciudadanos manifiesta desprotección en al menos 3 de los 4 ítems que conforman el índice de inseguridad.

Si bien la literatura establece la disponibilidad de recursos económicos y el estatus social como mecanismos de protección frente al delito, mitigando la percepción de vulnerabilidad en las clases sociales acomodadas, nuestros datos informan leves diferencias entre los grupos extremos en la escala de ingresos. No obstante se observan diferencias estadísticamente significativas [tind $(1345)=5,322 ; \mathrm{p}=0,001$ ], estas exhiben un reducido tamaño del efecto [Cohen's d=0,41], en particular cuando se compara con el registrado por otras dimensiones.

Por su parte, el perfil de la dimensión Trabajo se caracteriza, primero, por tener un índice general menos acentuado que las dimensiones Delincuencia, Ingresos y Salud, y segundo, por contar con similares puntuaciones entre estratos económicos. Aun cuando en términos desagregados las preocupaciones en torno al trabajo manifiestan cierto sesgo de clase en razón de la naturaleza del ítem, estas puntuaciones se compensan a nivel de promedio general y 
estructuran la dimensión Trabajo, junto con Delincuencia, como fuente compartida de incertidumbre por donde se transversaliza la sensación de inseguridad humana.

\section{Inseguridad en Trabajo}

En torno al trabajo y sus indicadores, Chile se encuentra enmarcado en una suerte de paradoja; si bien mantiene adecuados índices macroeconómicos plasmados en un crecimiento sostenido, una inflación controlada y una tasa de desempleo inferior a dos dígitos desde hace más de 20 años, existe en la población que integra la fuerza de trabajo una fuerte percepción de incertidumbre (Tabla 2).

Tabla 2: Inseguridad vinculada al Trabajo

\begin{tabular}{|c|c|c|c|c|c|c|c|}
\hline & \multicolumn{3}{|c|}{ Sexo } & \multicolumn{3}{|c|}{ NSE } & \multirow[b]{2}{*}{ Gral. } \\
\hline & Hombre & Mujer & Sig. & ABC1 & D y E & Sig. & \\
\hline - Obtenerlo 1 & 74,4 & 75,2 & - & 42,8 & 76,7 & $* * *$ & 74,9 \\
\hline - Perderlo ${ }^{2}$ & 28,6 & 26,3 & - & 7,9 & 32,7 & $* * *$ & 27,8 \\
\hline - Recuperarlo 1 & 58,1 & 63,3 & - & 47,9 & 61,9 & - & 59,9 \\
\hline - Cambiarse ${ }^{3}$ & 50,3 & 52,6 & - & 33,3 & 53,9 & $* *$ & 51,1 \\
\hline
\end{tabular}

Nota: 1= "muy difícil"/“difícil"; 2="poca confianza"/“ninguna confianza"; 3= "poco posible"/"nada posible"; Sig.= Significación estadística; Gral.= porcentaje respecto del total de población encuestada; $-=$ Contraste no significativo; $* *=$ Significación estadística al 95\%; ***= Significación estadística al $99 \%$.

Elaboración propia con base en los datos PNUD sobre Bienestar Subjetivo en Chile (2012).

Muy a pesar de la imagen exitosa anunciada por las cifras de la economía chilena, vastos sectores no se sienten partícipes de este desarrollo ni se encuentran igualmente integrados a sus redes, existiendo un evidente desajuste entre las condiciones objetivas, constituidas por índices macroeconómicos, y las subjetivas, conformadas por la sensación de (in)seguridad. Se manifiesta desconfianza respecto de la real capacidad que tiene el mercado laboral de absorber la mano de obra disponible, sea para insertarse laboralmente entre quienes buscan trabajo (74,9\%) o para recuperarlo en caso de ser desvinculado (59,9\%); así mismo, 1 de cada 2 ocupados $(51,1 \%)$ manifiesta escasas posibilidades de migrar hacia un trabajo que le ofrezca mayores garantías de seguridad.

Los ítems que conforman la dimensión Trabajo no reportan diferencias estadísticamente significativas con base al sexo [p>0,05], pero sí en razón al segmento socioeconómico de pertenencia. Si bien las incertidumbres vinculadas al empleo en la generalidad trascienden los adscritos estatus de clase, se instalan con mayor fuerza en la población de menores ingresos, 
particularmente en las oportunidades percibidas para encontrar trabajo $[\mathrm{X} 2(3)=27,720$; $\mathrm{p}=$ $0,000]$ y conservarlo $[\mathrm{X} 2(3)=15,152 ; \mathrm{p}=0,002]$.

Con la demanda de flexibilidad laboral que impone el escenario internacional y su competitividad, la inseguridad se acentúa. El otrora relevante vínculo entre satisfacción y estabilidad en el empleo ha cedido campo a la incertidumbre; los procesos de desregulación de mano de obra y realización de negocios con base a una matriz de contratos temporales (World Bank, 2007) han instalado como ventaja comparativa del currículum la desapropiación identitaria con las fuentes de empleo. El constante desajuste entre las expectativas personales y las posibilidades que ofrece el mercado del trabajo motiva la migración en quienes cuentan con altas cualificaciones e instala frustración en quienes no, presionando la reconfiguración del sujeto como mercancía, la monetización de sus competencias y el sentimiento de desafección con los ideales de protección y bienestar laboral colectivo.

No se trata necesariamente que los indicadores objetivos del trabajo en Chile se hayan deteriorado, sino más bien que se han modificado las condiciones en que este se realiza, lo que deriva un cambio de relación del sujeto con el empleo. Proceso adaptativo que, además de resistencia, genera natural malestar subjetivo. Así, el trabajador se hace cargo de su sentimiento de vulnerabilidad como connatural de su status, emprendiendo en solitario las medidas remediales necesarias para acortar la brecha entre las condiciones que instala la modernidad y sus capacidades personales para vivirla, haciendo de la angustia un evento no siempre pasajero.

\section{Inseguridad por Delincuencia}

La perspectiva multidimensional de la inseguridad, pese a expandir el análisis de la incertidumbre a campos de la vida social otrora considerados estables o donde los derivados de la duda se aceptaban como inofensivos, sigue teniendo como eje o clavija central la delincuencia. La victimización ciudadana, la percepción de la inseguridad y el miedo al delito se constituyen en problemas centrales en diferentes partes del mundo y en campos tan diversos como la sociología, la economía, la criminología y la psicología. No obstante, en el contexto nacional la percepción de malestar subjetivo se instala con relativa independencia de la manifestación real del fenómeno. Los estudios comparativos dan cuenta de una atenuación de las cifras que objetivan la seguridad ciudadana, en contraposición al aumento en la sensación de riesgo declarado por las personas (PNUD, 2013; Dammert y Lagos, 2012). 
Tabla 3: Inseguridad vinculada a la Delincuencia

\begin{tabular}{|c|c|c|c|c|c|c|c|}
\hline & \multicolumn{3}{|c|}{ Sexo } & \multicolumn{3}{|c|}{ NSE } & \multirow[b]{2}{*}{ Gral. } \\
\hline & Hombre & Mujer & Sig. & $\mathrm{ABC} 1$ & D y E & Sig. & \\
\hline - Inseguridad en el hogar ${ }^{1}$ & 59,2 & 64,0 & $* *$ & 70,3 & 59,4 & $* * *$ & 61,7 \\
\hline - Inseguridad vía pública ${ }^{1}$ & 78,9 & 80,9 & - & 92,2 & 77,9 & $* * *$ & 79,9 \\
\hline - Migración residencial ${ }^{2}$ & 63,0 & 69,5 & $* * *$ & 28,1 & 72,1 & $* * *$ & 66,3 \\
\hline - Recibir justicia ${ }^{3}$ & 86,1 & 87,7 & $* *$ & 67,1 & 88,0 & $* * *$ & 86,9 \\
\hline - Victimización ${ }^{4}$ & 18,4 & 18,6 & - & 23,1 & 18,2 & - & 18,5 \\
\hline
\end{tabular}

Nota: 1= "muy probable"/"medianamente probable"; $2=$ "poco posible"/"nada posible"; $3=$ "poca confianza"/"nada de confianza"; 4= "una vez"/"más de una vez"; Sig.= Significación estadística; Gral.= porcentaje respecto del total de población encuestada; -= Contraste no significativo; **= Significación estadística al 95\%; ***= Significación estadística al $99 \%$.

Elaboración propia con base en los datos PNUD sobre Bienestar Subjetivo en Chile (2012).

Al respecto, la Tabla 3 informa que una alta proporción de la población se siente expuesta al delito en la vía pública $(79,9 \%)$, sentimiento de inseguridad que permea los límites del hogar $(61,7 \%)$, con una nula o escasa confianza en la protección de la justicia (86,9\%). La sensación de vulnerabilidad frente al delito está generalizada, registrando grandes diferencias por nivel socioeconómico [Cohen's d=0,41], mientras las observadas con base al género son atenuadas [Cohen's d=0,16].

La segmentación territorial distribuye arbitrariamente las amenazas y obstáculos para la protección, evidenciándose una mayor percepción de vulnerabilidad en los sectores pobres respecto de recibir justicia $[\mathrm{X} 2(3)=36,593 ; \mathrm{p}=0,000]$ y migrar hacia barrios percibidos como más seguros $[\mathrm{X} 2(3)=82,477 ; \mathrm{p}=0,000]$; mientras que para los sectores de mayores ingresos, quienes reportan más alta recurrencia de victimización $(23,1 \%)$, sus miedos se centran en ser víctima de asalto o robo en el hogar $[X 2(3)=24,924 ; p=0,000]$ o la vía pública $[X 2(3)=24,444$; $\mathrm{p}=0,000]$, siéndoles este último espacio particularmente peligroso $(92,2 \%)$.

El microtráfico, la precarización de las condiciones de habitabilidad y la escasa accesibilidad a servicios públicos de atención policial y sanitaria, deterioran el sentido de pertenencia al barrio y facilitan su transformación en espacio crimípeto, es decir, un contexto residencial que entrega oportunidades para delinquir y efectuar actividades ilícitas (Vozmediano y San Juan, 2010).

En los sectores vulnerables no solo el sentimiento de desafección institucional y denegación de justicia es mayor $(88,0 \%)$, sino que además este desamparo es acompañado por 
la dificultad para migrar hacia barrios percibidos como más seguros $(72,1 \%)$. La sensación de inseguridad se instala con mayor intensidad respecto de la vía pública $(79,9 \%)$, sobre todo entre los sectores de mayores ingresos $(92,2 \%)$, situación que fuerza el cambio en hábitos cotidianos ahora percibidos como inseguros e incide en la implementación de medidas de resguardo en el hogar.

La inseguridad, aparente o real, termina por ser tan dañina para el bienestar y la cohesión social como el delito mismo (Rodríguez, Padilla y Durán, 2017), instala la desconfianza interpersonal al percibir al otro como amenaza, situación que deriva en la fragmentación de las relaciones sociales y el abandono de los espacios públicos para confortarse en la privacidad del hogar, aunque ello no implique necesariamente sentirse física y emocionalmente más a salvo.

El estado de inseguridad percibida, teniendo una base estadística que la ampara, no correlaciona con el hecho de haber sido objeto de algún delito, con la intensidad deseada. Más allá del cluster de referencia, la inseguridad subjetiva se eleva muy por sobre las cifras de victimización (18,5\%). En efecto, el sentimiento de victimización se asocia más con las creencias y expectativas que los sujetos construyen con base a la mediatización que con las cifras de delincuencia que las instituciones de control recogen sistemáticamente (Olavarría, 2006; Carrión, 2014). Esta configuración modifica la perspectiva tradicional que definía a la víctima como aquella persona que sufre algún delito o perjuicio (Dammert, 2004), para adentrarse hacia causas y motivos de carácter más subjetivo, diversificando sus fuentes y amenazas, lo que vuelve su condición analítica más compleja y relativa (Gallardo, 2014).

Cabe hacer presente aquí que si bien el miedo es amplificado por la exposición al sensacionalismo del mass media, la sensación de inseguridad está lejos de ser una mera construcción social alimentada por los medios. El mass media actúa como caja de resonancia que refuerza el temor dada la natural tendencia ciudadana a empatizar y sensibilizar con la experiencia ajena, particularmente cuando esta es traumática y se poseen características similares a las víctimas (Hipp, Petersilia y Turner, 2010; Gómez, 2014; Focás y Rincón, 2016).

El miedo al delito, amplificado o real, el sentimiento de inseguridad, la alteración de pautas de conducta ahora consideradas de riesgo, las medidas de resguardo del hogar, la pérdida de confianza en las instituciones y el sentimiento de desafección perfila al ciudadano como un sujeto aislado, haciéndose cargo de sí mismo a pesar de vivir en sociedad. Se instala así una percepción de vulnerabilidad que refuerza idénticas expresiones en otras esferas del malestar 
humano y hace del miedo una manifestación transversalizada (Rodríguez, Padilla y Durán, 2017).

\section{Inseguridad en Ingresos}

Con independencia relativa del nivel de especialización, credenciales educativas, formalidad contractual y antigüedad en el empleo, los trabajadores se incorporan como una identidad particularmente vulnerable. Sentimiento que se traduce en una mayor inseguridad económica en razón de los reducidos apoyos institucionales para absorber los riesgos que se derivan de la cesantía, los reducidos montos del salario y pensiones, y el encarecimiento del costo de vida.

Tabla 4: Inseguridad vinculada a los ingresos

\begin{tabular}{|c|c|c|c|c|c|c|c|}
\hline & \multicolumn{3}{|c|}{ Sexo } & \multicolumn{3}{|c|}{ NSE } & \multirow[b]{2}{*}{ Gral. } \\
\hline & Hombre & Mujer & Sig. & $\mathrm{ABC} 1$ & D y E & Sig. & \\
\hline - Solvencia económica ${ }^{1}$ & 39,5 & 43,3 & $* *$ & 6,8 & 48,1 & $* * *$ & 41,4 \\
\hline - Acceso crédito formal ${ }^{1}$ & 55,3 & 62,5 & $* * *$ & 23,6 & 66,3 & $* * *$ & 59,0 \\
\hline - Consejo económico ${ }^{1}$ & 43,5 & 51,3 & $* * *$ & 13,6 & 53,4 & $* * *$ & 47,5 \\
\hline - Acceso a crédito informal ${ }^{1}$ & 61,5 & 66,4 & $* * *$ & 28,4 & 70,1 & $* * *$ & 64,0 \\
\hline - Incremento ${ }^{2}$ & 47,4 & 56,4 & $* * *$ & 12,2 & 57,9 & $* * *$ & 52,0 \\
\hline - Suficiencia post-jubilación ${ }^{3}$ & 66,3 & 73,1 & $* * *$ & 34,2 & 78,1 & $* * *$ & 69,7 \\
\hline - Sobreendeudamiento ${ }^{4}$ & 20,3 & 23,6 & $* *$ & 6,7 & 15,7 & $* * *$ & 22,0 \\
\hline - Riesgo morosidad ${ }^{5}$ & 67,5 & 74,9 & $* * *$ & 52,2 & 73,6 & $* * *$ & 71,4 \\
\hline
\end{tabular}

Nota: 1= "poco probable"/"nada probable"; $2=$ "poco posible"/"nada posible"; $3=$ "esos ingresos no le permitirán cubrir su NBS"/"esos ingresos le permitirán cubrir sólo sus NBS"; 4= "tiene deudas y no las está pudiendo pagar"/"tiene deudas que a veces puede pagar y otras veces no"; $5=$ "muy preocupado"/"algo preocupado"; Sig.= Significación estadística; Gral.= porcentaje respecto del total de población encuestada; **= Significación estadística al 95\%; ***= Significación estadística al 99\%.

Elaboración propia con base en los datos PNUD sobre Bienestar Subjetivo en Chile (2012).

El trabajo, en particular el de carácter asalariado, se constituye en la principal fuente generadora de ingresos, incluso dentro de las familias más pobres. La vulnerabilidad económica se estructura con base a la insuficiencia de rentas reportadas por el trabajo remunerado y no necesariamente como expresión de la falta de una fuente de empleo (Tabla 4).

Las bajas remuneraciones laborales se circunscriben a la satisfacción de necesidades básicas haciendo poco probable la existencia de remanentes que pudieran invertirse en el desarrollo de iniciativas familiares $(41,4 \%)$ y tampoco se avizora la probabilidad de que en el futuro cercano se generen incrementos (52\%). La insuficiencia de ingresos familiares que 
permitan hacer realidad la realización de proyectos que el grupo familiar se haya planteado (Solvencia económica) se constata con ostensible intensidad en los sectores más vulnerables $(58,1 \%)$, marcando significativas diferencias respecto del segmento de comparación [X2(3)= 75,038; $\mathrm{p}=0,000]$.

Precariedad de los ingresos del trabajo que provoca que se instale con mayor intensidad el sentimiento de inseguridad en quienes abandonan por edad el mercado laboral para vivir de los ahorros previsionales $(69,7 \%)$, particularmente entre los más pobres $(78,1 \%)$. En efecto, la jubilación se constituye en una manifestación de potencial vulnerabilidad económica y pauperización de una amplia masa de trabajadores y sus familias en razón de las exiguas tasas de reemplazo, precisando de una continua y creciente transferencia estatal a fin de garantizar pensiones mínimas.

El sentimiento de vulnerabilidad económica los hace autopercibirse como un agente riesgoso y escasamente atractivo para acceder al crédito, sea este de carácter formal (59\%) o informal (64\%), particularmente entre los más pobres [X2(3)=95,964; $p=0,000]$.

Cabe hacer presente aquí que los componentes que estructuran la dimensión Inseguridad de Ingresos están en su manifestación fuertemente condicionados por el factor socioeconómico, siendo precisamente los más pobres quienes expresan mayor vulnerabilidad en cada uno de los ítems de la dimensión $[\mathrm{p}<0,05]$. Cabe hacer presente que esto no significa necesariamente que los más pobres no sean objeto de crédito, más bien es esta misma precariedad económica y la búsqueda por solventar consumo la que ha suscitado un fuerte endeudamiento y consiguiente morosidad que inhibe la posibilidad de acceder a préstamos.

En las últimas décadas entidades financieras y de retail han masificado el acceso a mecanismos de consumo vía crédito, instalando niveles de endeudamiento que paulatinamente han generado inquietud entre la ciudadanía (Echeverría, 2014). En efecto, nuestros datos informan que un $22 \%$ de la población general y un $25,7 \%$ de quienes pertenecen a los sectores D y E manifiesta que tiene deudas que no puede pagar o bien lo hace en forma intermitente, lo que deriva repactaciones, aumento de intereses y prolongación de la deuda.

La facilidad para acceder al crédito significa una oportunidad para incorporarse a las redes de consumo y adquirir bienes y servicios que de otro modo sería imposible, no obstante, esta inclusión es endeble, simbólica en el horizonte de posibilidades que abre pero muy real en sus riesgosas consecuencias, un oropel inaugurado como status connatural a las categorías de 
ciudadano en sociedades modernas. El consumo, indicador de vigor y buena salud de la economía nacional, con base al endeudamiento se hace insostenible a largo plazo al traspasar un umbral de solvencia, configurando un círculo de deuda difícil de sortear, generando problemas en la salud psicológica de los individuos (Echeverría, 2014; Salgado y Chovar, 2010).

El sobreendeudamiento tiene efectos nocivos sobre el patrimonio económico y bienestar subjetivo familiar, donde un $71,4 \%$ de los entrevistados se manifiesta preocupado por no poder cumplir con sus entidades acreedoras, situación en que huelga referirse al estrés colectivo que esto puede significar, ya que el acudir a créditos de forma constante puede acabar con sentimientos de agobio, poco control en la vida económica y constante tensión; consecuencias que merman la felicidad (Vandone, 2009).

\section{Inseguridad en Vivienda}

Si bien la política habitacional en Chile ha tenido un impacto positivo en el acceso y saneamiento básico de viviendas para la población, aún persisten problemáticas vinculadas a las condiciones de habitabilidad (MINVU, 2004; Rodríguez y Sugranyes, 2004). En forma paradojal, junto con aumentar las cuotas de cobertura y el sueño de la casa propia, los programas de vivienda social profundizaron la segmentación territorial mediante la disposición periférica de las residencias populares, alejadas de las fuentes de trabajo y servicios comunitarios, transfigurando la problemática habitacional desde el déficit de tenencia hacia las condiciones de habitabilidad y entorno.

Tabla 5: Inseguridad vinculada a la Vivienda

\begin{tabular}{|c|c|c|c|c|c|c|c|}
\hline & \multicolumn{3}{|c|}{ Sexo } & \multicolumn{3}{|c|}{ NSE } & \multirow[b]{2}{*}{ Gral. } \\
\hline & Hombre & Mujer & Sig. & $\mathrm{ABC} 1$ & D y E & Sig. & \\
\hline - Infraestructura ${ }^{1}$ & 20,9 & 23,2 & - & 0 & 27,8 & $* * *$ & 22,1 \\
\hline - Servicios básicos ${ }^{1}$ & 12,5 & 13,2 & - & 0 & 16,3 & $* * *$ & 12,9 \\
\hline - Aspecto ${ }^{1}$ & 20,4 & 23,2 & - & 0 & 28,0 & $* * *$ & 21,8 \\
\hline - Privacidad ${ }^{1}$ & 17,9 & 25,6 & $* * *$ & 3,3 & 27,5 & $* * *$ & 21,8 \\
\hline - Mejoramiento habitacional ${ }^{2}$ & 55,8 & 66,0 & $* * *$ & 22,0 & 67,6 & $* * *$ & 61,0 \\
\hline
\end{tabular}

Nota: 1="inadecuado a sus necesidades"/"muy inadecuado a sus necesidades"; $2=$ "poco posible"/"nada posible"; Sig.= Significación estadística; Gral.= porcentaje respecto del total de población encuestada; $-=$ Contraste no significativo;**= Significación estadística al 95\%; ***= Significación estadística al 99\%.

Elaboración propia con base en los datos PNUD sobre Bienestar Subjetivo en Chile (2012). 
La constitución de guetos, aun contando con dotación de servicios de saneamiento básicos, inhibe las capacidades de acumulación de capital social, por cuanto quien adquiere una vivienda adquiere también un conjunto de redes simbólicas asociadas al entorno comunitario, vecinal e institucional próximo. En el espacio residencial los agentes tienen la posibilidad de incorporar valor agregado al campus, brindando oportunidades y sentimientos de seguridad que van más allá de la delimitación perimetral de la vivienda.

La Tabla 5 reporta que la inseguridad en cuanto a vivienda y entorno es un fenómeno social casi totalmente perteneciente a segmentos de menores ingresos, siendo posible inferir que la percepción negativa de habitabilidad está estrechamente relacionada con ser pobre $[\mathrm{p}<0,000]$. Los grupos de los deciles más bajos tienden a vivir en barrios periféricos cuando no marginales, en casas cuyo deterioro y/o construcción precaria induce a los habitantes a percibirlas negativamente en términos de calidad material $(27,8 \%)$, estéticamente mal evaluadas $(28,0 \%)$ y con precarias condiciones de espacio y aislamiento (27,5\%). Menguada percepción de bienestar que se acentúa frente a la imposibilidad de movilidad residencial o inversión de recursos para la mejora (67,6\%). Por su parte, en los residentes $\mathrm{ABC} 1$ las condiciones de precariedad tanto en infraestructura, servicios básicos, aspecto y habitabilidad, son prácticamente inexistentes.

Los datos informan que $21,8 \%$ de la población siente que su espacio personal y privacidad son inadecuados, siendo las mujeres $[\mathrm{X} 2(3)=22,367 ; \mathrm{p}=0,000]$ y los segmentos pobres de la población $[\mathrm{X} 2(3)=72,707 ; \mathrm{p}=0,000]$ quienes presentan mayores índices de incomodidad. La menor privacidad señalada por mujeres es relevante toda vez que, dada la construcción social del género y la distribución sexual de roles, es ella quien permanece más tiempo en casa y está a cargo de la crianza, mantención y cuidado del resto de miembros. Estas precarias condiciones de habitabilidad, en particular el hacinamiento y la pauperización del entorno y redes, constituyen el principal factor de menoscabo en temas de vivienda en Chile, tomando en cuenta que necesidades de saneamiento básico han sido considerablemente cubiertas en el país. Vulnerabilidad barrial que se corresponde con una de las expresiones más claras de la pobreza y su reproducción, pues implica un mal ambiente para el desarrollo escolar, social y personal de niños, niñas y adolescentes (MINVU, 2004).

La inseguridad humana vinculada a la vivienda hace menester visualizar el dilema en que se encuentran las familias carenciadas en sus condiciones de habitabilidad. La política habitacional actual que rige la provisión de viviendas sociales prolonga, por sus características 
constructivas y emplazamiento, la incomodidad y malestar subjetivo. Por falta o especulación del suelo, las viviendas populares son proyectadas en la periferia de las ciudades, provocando dificultades de acceso al transporte, trabajo, recintos educacionales y comercio; aislamiento que representa otra forma de segregación.

\section{Inseguridad en Salud}

Con muy pocas excepciones a la regla, los países con mayores índices de desigualdad en la distribución de riquezas entre sus habitantes son, a la vez, aquellos que tienen las mayores diferencias en sus criterios de acceso, calidad y oportunidad en la atención médica. Chile no es ajeno a esta tendencia, pues a pesar de sus auspiciosos indicadores macroeconómicos, se posiciona como uno de los países con mayor inequidad en la distribución de la riqueza, lo que repercute en la cobertura de necesidades básicas de salud (OMS, 2009; Gonzáles, 2017).

Tabla 6: Inseguridad vinculada a la Salud

\begin{tabular}{lccccccc}
\hline & \multicolumn{9}{c}{ Sexo } & \multicolumn{7}{c}{ NSE } \\
\cline { 2 - 8 } & Hombre & Mujer & Sig. & ABC1 & D y E & Sig. & Gral. \\
\hline Accesibilidad $^{1}$ & 65,4 & 72,8 & - & 0 & 73,0 & $* * *$ & 68,8 \\
Elegibilidad $^{1}$ & 72,2 & 76,9 & $* * *$ & 26,6 & 81,9 & $* * *$ & 74,7 \\
Oportunidad $^{2}$ & 65,5 & 59,3 & - & 9,8 & 65,2 & $* * *$ & 57,9 \\
Asequibilidad $^{2}$ & 67,9 & 72,2 & $* * *$ & 22,8 & 77,6 & $* * *$ & 70,1 \\
Calidad $^{2}$ & 57,3 & 59,5 & - & 0 & 65,6 & $* * *$ & 58,4 \\
\hline
\end{tabular}

Nota: $1=$ "poco posible"/“nada posible"; 2 = "poca confianza"/"nada de confianza"; Sig.= Significación estadística; Gral.= porcentaje respecto del total de población encuestada; $-=$ Contraste no significativo; $* * *=$ Significación estadística al $99 \%$.

Elaboración propia con base en los datos PNUD sobre Bienestar Subjetivo en Chile (2012).

De acuerdo a la Tabla 6, de quienes adscriben a algún programa de salud, una alta proporción reporta incertidumbre sobre la posibilidad de cubrir costos médicos $(70,1 \%)$, recibir atención oportuna $(57,9 \%)$ y de calidad $(58,4 \%)$ frente a alguna urgencia; incluso, la cualidad de libre elección pregonada por el sistema de salud se vislumbra fuertemente cuestionada por gran mayoría de la población adscrita $(74,7 \%)$.

El sentimiento de vulnerabilidad pervive en el ciudadano, por cuanto no es la ausencia de una institucionalidad lo que instala la sensación de riesgo, tal como la carencia de seguro médico, sino la precariedad en términos de oportunidad, asequibilidad y calidad con que esta funciona. La prevalencia de lógicas de mercado en salud, propias de la herencia de reformas de 
los 80’, segmenta servicios sociales asociados a derechos en razón de la capacidad de pago y presupuesto familiar, estimulando el crecimiento del sector privado y el financiamiento individual (Accorsi y Alarcón, 2012).

El sistema público, al cual adscribe la gran mayoría de la población, presenta endémicas y estructurales problemáticas vinculadas a su dotación profesional y tecnológica, disponibilidad presupuestal, estrategias de organización y modelo de gestión, que producen colapsadas listas de espera para exámenes, intervenciones quirúrgicas y exploraciones instrumentales, restringido acceso a especialistas y un servicio de urgencias atochado (Goic, 2015).

De esta manera, el gran problema que enfrenta el sistema de salud y acentúa la sensación de malestar subjetivo son las brechas producidas por la inequidad instalada con ocasión de su mercantilización (Vergara, 2007). En efecto, los indicadores de inseguridad humana en esta dimensión están fuertemente condicionados por el nivel socioeconómico $[\mathrm{p}<0,000]$, mientras mayor es la vulnerabilidad socioeconómica mayor es la precariedad en términos de accesibilidad, elegibilidad, oportunidad, asequibilidad y calidad de la atención médica recibida.

\section{Inseguridad en Educación}

Como extensión ineluctable del progreso de la modernidad, la ciencia y las tecnologías, el desarrollo y perfeccionamiento intelectual de la población se ha vuelto objetivo imperante, donde lo sustancial es optimizar las oportunidades de acceso, adquisición de competencias e inserción profesional en la ciudadanía. En tal sentido, los aparatos del Estado chileno han procurado equidad y calidad en sus servicios educativos, actuando como facilitadores de recursos y movilidad, aun cuando la realidad manifiesta un grueso quiebre al respecto, presentando dificultades para instalar adecuada y pertinentemente competencias que favorezcan el desempeño en una sociedad cada vez más informatizada (Tedesco, 2008).

En términos educativos, Chile tiene un sistema profundamente segmentado y desigual. Con una lógica de subsidio a la demanda, donde los fondos siguen a los alumnos, se instala una fuerte competencia entre instituciones, lo que abre paso a la mercantilización, privatización y provisión desigual del servicio educativo (Donoso y Arias, 2012; Corvalán y García-Huidobro, 2015; Bellei, 2015; Páez y Kremerman, 2016). La segregación escolar tiene un impacto negativo en el aprendizaje y expectativas de los estudiantes, a la vez que limita las oportunidades para valorar la diversidad, generar sentimientos de pertenencia y construir ciudadanía, constituyendo la institución educativa antesala y prolongación de injusticia social (Murillo y Duk, 2016). 
Tabla 7: Inseguridad vinculada a Educación

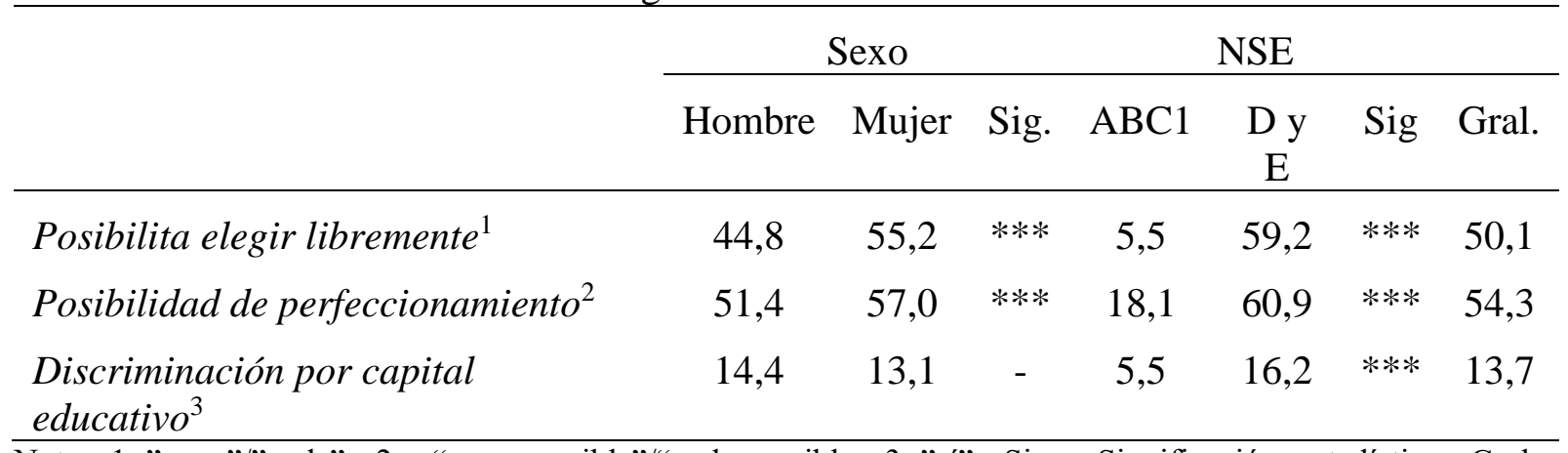

Nota: 1="poco"/"nada"; 2= "poco posible"/"nada posible; 3="sí"; Sig.= Significación estadística; Gral.= porcentaje respecto del total de población encuestada; -= Contraste no significativo;**= Significación estadística al 95\%; $* * *=$ Significación estadística al 99\%.

Elaboración propia con base en los datos PNUD sobre Bienestar Subjetivo en Chile (2012).

Resulta paradójico que en un sistema que propugna la libre elección educativa 1 de cada 2 personas $(50,1 \%)$ manifieste que el nivel educativo alcanzado, aun pudiendo ser alto, no le posibilita elegir libremente (Tabla 7). Lo que estaría a la base de esta desigualdad percibida no es el capital escolar en sí mismo, sino más bien la calidad de la experiencia educativa y redes construidas en el proceso de acumulación. Desigualdad que comprende un cierre social donde las capas socioeconómicas más acomodadas perciben, con ocasión de la calidad del capital humano acumulado, mayores posibilidades para tomar decisiones en su vida $[\mathrm{X} 2(3)=120,410$; $\mathrm{p}=0,000]$.

Entendiendo la educación como proceso, la desigualdad en esta materia se hace posible de revertir mediante la disposición de mecanismos de perfeccionamiento en un contexto de desarrollo profesional continuo o educación para toda la vida, empero, estas oportunidades se encuentran además de limitadas fuertemente segmentadas por nivel socioeconómico. En efecto, un $49,6 \%$ de la muestra señala escasas posibilidades para aprender algo nuevo que mejore su desempeño en el mundo actual, incertidumbre fuertemente presente en los sectores pobres $[\mathrm{X} 2(3)=70,072 ; \mathrm{p}=0,000]$.

Aunque con menor prevalencia respecto de los otros componentes de inseguridad humana vinculada a educación, la experiencia de discriminación se evidencia en un 13,7\% de la población encuestada, y claramente más acentuada en los grupos socioeconómicos D y E $[\mathrm{X} 2(3)=7,455 ; \mathrm{p}=0,002]$. El déficit de capital humano en cuanto a años de estudio y calidad de la experiencia educativa tiene su correlato en la depreciación y estigmatización de las credenciales que hacen determinados empleadores con base a la procedencia, años invertidos, 
títulos y grado alcanzado; atributos que condicionan comportamientos discriminatorios y prejuiciados hacia los segmentos más pobres, incluso a pesar del capital humano acumulado.

Por ello, el sistema educativo y su funcionamiento actual parecen incapaces de frenar, cuando no sostener, la sensación de inseguridad en la población, en especial si se trata de entregar las herramientas necesarias para poder elegir qué hacer en la vida o nuevas competencias que faciliten un desempeño satisfactorio (Donoso, 2006).

\section{Comentarios}

En términos generales, la inseguridad parece vehiculada por los ciudadanos hacia cada una de las dimensiones que componen la vida moderna, un sentimiento más en el catálogo de respuestas frente a la contingencia. No obstante el nivel de acumulación de capital humano, prestigio y estatus actúa como factor de protección para la contención y mitigación de la inseguridad, ello no evita que las personas perciban la vulnerabilidad como algo cercano, especialmente cuando ocurre algún inconveniente vinculado a Delincuencia, Salud o Ingresos. Ello refuerza el argumento que la inseguridad dista de ser patrimonio exclusivo de las clases más pobres o que está circunscrita solamente a la percepción de victimización.

Aun cuando el miedo al delito tiene una base estadística que la objetiviza y ampara, esta sensación no se corresponde linealmente con la disminución en la cifra de delitos contra la propiedad y las personas que exhiben los reportes de seguridad ciudadana los últimos años. El sentimiento de vulnerabilidad persiste aun cuando sus expresiones materiales se mantienen o decaen, lo cual pone de manifiesto la importancia de la dimensión subjetiva, donde más que cifras son las narrativas mediáticas y discursos de economía política los que sostienen el miedo a la Delincuencia. En esta dimensión destacan dos fenómenos: por una parte, la percepción popular de la vía pública como sitio de victimización, favorecedor de acciones delictivas; y por otro, la desconfianza en que los aparatos de justicia son capaces de cumplir adecuadamente su labor de protección y compensación en caso de ser requeridos.

Sin embargo y como hemos expuesto, la preocupación de los chilenos y chilenas se ha propagado hacia otras áreas, entre las que destacan Salud, Educación, Trabajo e Ingresos, debido a relevancia que tienen las actividades allí realizadas para definir un sentido de bienestar, que incluyen lograr una vida larga y saludable, contar con el capital humano necesario para desenvolverse en la sociedad y alcanzar un nivel de vida que resulte satisfactorio. 
En este escenario y según reportan los ciudadanos, el Trabajo se caracterizaría por ser un territorio inestable y volátil, donde las posibilidades de obtener empleo disminuyen y que, incluso de conseguirlo, no existe seguridad en ser capaz de mantenerlo o cambiarlo, ni siquiera la experiencia adquirida otorga confianza en que podrían recuperarlo si se pierde; en cuanto a Ingresos lo que provoca incertidumbre es la incapacidad para cumplir compromisos crediticios y sostener un nivel de vida aceptable durante el período de jubilación, donde se agotan las fuentes de renta y perceptores de ingreso familiar.

Respecto a Vivienda, la inseguridad se proyecta bajo la imposibilidad de poder migrar hacia otros barrios o adecuar materialmente el hogar según las expectativas familiares, situación que aumenta la frustración entre quienes habitan territorios pauperizados. En Salud, el malestar se encuentra en las oportunidades de escoger dentro del sistema una modalidad que se ajuste a las necesidades de protección y estar a resguardo de contingencias recibiendo una atención oportuna, de calidad y asequible, sentimiento de vulnerabilidad que persiste pese a la disponibilidad de seguro médico. Por último, la dimensión Educativa proyecta insatisfacción debido a que las herramientas de capital humano adquiridas tienen escaso valor de utilidad para elegir libremente qué hacer, además de las restricciones que presenta a los anhelos de perfeccionamiento.

Las implicancias de la inseguridad humana se dejan sentir con fuerza en las medidas políticas y ciudadanas que los organismos del Estado ponen en curso bajo categorías del plan de gobierno, donde la repulsa popular de actos delictivos puede tender hacia la aseveración de sanciones penales en lugar de una discusión sobre sus causas y factores, tal y como es ejemplo el conjunto de medidas que incluye la agenda corta contra la delincuencia y su endurecimiento de las condenas, masificación de los controles de identidad preventivo y re-tipificación de delitos contra la autoridad, las fuerzas de orden y seguridad.

El desafío de educar y preparar a los ciudadanos para que sean capaces de sostener los proyectos de desarrollo nacional parece yuxtaponerse con el de promover el desarrollo humano, por cuanto las personas, siendo parte de un sistema educativo y de integración laboral, creen que las herramientas de capital humano adquiridas no alcanzan para hacer aquello que se proponen en la vida o los hace felices.

En suma, lo que la Inseguridad Humana plantea es el proceso de reinscripción analítica del miedo, temor e incertidumbre como características inherentes a la construcción y desarrollo 
de ciudadanía en tiempos modernos. En lo inmediato, encontramos que uno de los obstáculos para llevar a cabo esta propuesta es la hegemonía que ha logrado la delincuencia y sus derivados, arraigando en la población estrechas relaciones entre vulnerabilidad y malestar, entre el otro desconocido y la amenaza, como si ella fuese la única productora de descontento.

\section{Referencias}

Accorsi, E., \& Alarcón, A. (Edits.). (2012). Comisión de seguridad social y el sistema de salud en Chile. Problemas de salud y respuestas del sistema sanitario para Chile al año 2040 (págs. 35-38). Valparaíso: Oficina de publicación Cámara de Diputados de Chile.

Bauman, Z. (2015). Modernidad líquida. Buenos Aires: Fondo de Cultura Económica.

Beck, U. (2005). La teoría de la sociedad del riesgo reformulada.

Bellei, C. (2015). El gran experimento: Mercado y privatización de la educación chilena. Santiago: LOM.

Bourdieu, P. (2016). La distinción: criterio y bases sociales del gusto. Barcelona: Taurus.

Browne, M., \& Valenzuela, S. (2016). Temor a la delincuencia en Chile: ¿Una creación de los medios o una realidad que nace de la experiencia de la ciudadanía? Análisis longitudinal e individual de las teorías comunicacionales del cultivo y agenda setting. En B. Focás, \& O. Rincón, (In)seguridad, medios y miedos: una mirada desde las experiencias y las prácticas cotidianas en América Latina (págs. 117-156). Colombia: Universidad Icesi.

Carrión M., F. (2014). Violencia y medios de comunicación: populismo mediático. Revista Latinoamericana De Estudios De Seguridad(5), 7-12.

Carrión, F. (2005). La seguridad en América Latina y Europa. Quorum, 12, 21-28.

Castells, M. (2001). La era de la información: economía, sociedad y cultura (2da. ed., Vol. 1. La sociedad red). México: Siglo Veintiuno.

Centro de Estudios Públicos (CEP). (2015). Estudio Nacional de Opinión Pública N 75, Noviembre 2015. Santiago de Chile: Centro de Estudios Públicos .

Corvalán, J., \& García-Huidobro, J. (2015). La educación de mercado en Chile y su propuesta de superación. Cuadernos de educación(66), 1-16.

Cuadra, H., \& Florenzano, R. (2003). El Bienestar Subjetivo: Hacia una Psicología Positiva. Revista de Psicología de la Universidad de Chile, 12(1), 83-96.

Dammert, L. (2004). ¿Ciudad sin ciudadanos? Fragmentación, segregación y temor en Santiago. Eure, 30(91), 87-96.

- (2005). Violencia criminal y seguridad ciudadana en Chile. United Nations Publications.

Dammert, L., \& Lagos, M. (2012). La Seguridad Ciudadana. El problema principal de América Latina. Lima: Latinobarómetro.

Díaz, V., \& Ortiz, A. (2014). La ciudad y la arquitectura del miedo. Estudio conceptual comparativo entre el fraccionamiento habitacional cerrado de lujo contemporáneo y la bastida medieval. Revista nodo, 8(16), 25-42.

Donoso, S. (2006). Financiamiento y gestión de la educación pública chilena de los años 90. Cuadernos de Pesquisa, 36(27), 151-172. 
Donoso, S., \& Arias, O. (2012). Distribución desigual de las oportunidades educativas en el territorio y migración de la matrícula escolar: el caso de la región de Los Lagos. Estudios pedagógicos, 38(2), 35-54.

Echeverría, F. (2014). Endeudamiento y pobreza en Chile. Informe Social No1.

Esposito, R., \& Nancy, J. L. (2003). Communitas: origen y destino de la comunidad. Buenos Aires: Amorrortu editores.

Focás, B., \& Rincón, O. (2016). (In)seguridad, medios y miedos: una mirada desde las experiencias y las prácticas cotidianas en América Latina. Cali: Editorial Universidad Icesi y FES Comunicaciones.

Foucault, M. (2008). Vigilar y castigar: nacimiento de la prisión. México: Siglo Veintiuno.

- (2014). Los anormales. Buenos Aires: Fondo de Cultura Económica.

Fundación Paz Ciudadana (FPC). (2015). Balance de la delincuencia en Chile 2014: Radiografía del sistema de seguridad y justicia. Santiago de Chile: Fundación Paz Ciudadana.

Gallardo, R. (2014). Desorden, victimización y temor: estudio exploratorio sobre la relación entre la percepción de desorden y delito en Chile. Criminalidad, 56(3), 25-43.

Garay, S., \& Montes de Oca, V. (2011). La vejez en México: una mirada general sobre la situación socioeconómica y familiar de los hombres y mujeres adultos mayores. Perspectivas sociales, 13(1), 143-165. Obtenido de http://eprints.uanl.mx/8789/

Giddens, A. (1993). Consecuencias de la modernidad. Madrid: Alianza.

Gilbert, J. (2010). Introducción a la sociología. Santiago: LOM.

Goic, A. (2015). El Sistema de Salud de Chile: una tarea pendiente. Revista médica de Chile, 143(6), 774-786.

Gómez, A. (2014). ¿Populismo penal o falta de creatividad? Revista Latinoamericana De Estudios De Seguridad(11), 7-8.

Gonzáles, L. (2017). Desarrollo económico local: leyendas y realidades. Territorios(1), 9-24.

Hipp, J., Petersilia, J., \& Turner, S. (2010). Parolee recidivism in California: The effect of neighborhood context and social service agency characteristics. Criminology, 48(4), 947-979.

Larraín, J. (2005). ¿América Latina Moderna?: globalización e identidad. Santiago: LOM.

Ministerio de Vivienda y Urbanismo (MINVU). (2004). El déficit habitacional en Chile. Medición de requerimientos de vivienda y su distribución espacial. Santiago de Chile: Ministerio de Vivivenda y Urbanismo de Chile.

Moulian, T. (1997). Chile actual. Anatomía de un mito. Santiago de Chile: Lom Ediciones.

Moyano, E., \& Ramos, N. (2007). Bienestar subjetivo: midiendo satisfacción vital, felicidad y salud en población chilena de la Región Maule. Universum, 22(2).

Murillo, F., \& Duk, C. (2016). Segregación Escolar e Inclusión. Revista latinoamericana de educación inclusiva, 10(2), 11-13.

Olavarría, M. (2006). El crimen en Chile. Una mirada desde las víctimas. Santiago de Chile: RIL editores. 
Organización Mundial de la Salud (OMS). (2009). Indicadores para evaluar la protección social de la salud (el caso de Chile). Santiago de Chile: Fondo Nacional de Salud - Chile.

Paez, C., Peón, I., \& Ramírez, Y. (2018). Contexto de la seguridad ciudadana en América Latina y el Caribe: revisión de literatura (2007-2017). Rev. Cient. Gen. José María Córdova, 16(24), 83-106. Obtenido de https://revistacientificaesmic.com/index.php/esmic/article/view/360/249

Páez, A., \& Kremerman, M. (2016). Endeudar para gobernar y mercantilizar: el caso del CAE. Santiago de Chile: Fundacion Sol.

Programa de Nacionaes Unidas para el Desarrollo (PNUD). (1998). Informe de Desarrollo Humano en Chile. Las paradojas de la modernización. Santiago de Chile: Programa de las Naciones Unidas para el Desarrollo.

- (2012). Informe de Desarrollo Humano en Chile. Bienestar subjetivo: el desafío de repensar el desarrollo. Santiago de Chile: Programa de las Naciones Unidas para el Desarrollo.

- (2013). Trabajo decente e igualdad de género. Políticas para mejorar el acceso y la calidad del empleo de las mujeres en América Latina y el Caribe. Santiago de Chile: CEPAL, FAO, ONU Mujeres, PNUD, OIT.

- (2017). Chile en 20 años: Un recorrido a través de los Informes de Desarrollo Humano. Santiago de Chile: Programa de las Naciones Unidas para el Desarrollo.

Polomer, A. (2005). Seguridad Ciudadana y Sociedad en Chile Contemporáneo. Los delincuentes, las políticas y los sentidos de una sociedad. Revista de estudios históricos.

Pratt, M. L. (2000). "Des-escribir a Pinochet: desbaratando la cultura del miedo en Chile. Gale OneFile: Informe Académico.

Rodríguez, A., \& Sugranyes, A. (2004). El problema de vivienda de los“con techo”. EURE, 30(91), 53-65.

Rodríguez, C., Padilla, G., \& Durán, V. (2017). Sobre el miedo al delito y los otros miedos: el ciudadano-víctima y la inseguridad transversalizada. Política y Sociedad, 54(3), 781803.

Salgado, H., \& Chovar, A. (2010). "¿ Cuánto influyen las tarjetas de crédito y la deuda hipotecaria en el sobre endeudamiento de los hogares de Chile. Concepción : Departamento de Economía.

Schwartz, S. H. (2001). ¿Existen aspectos universales en la estructura y contenido de los valores humanos? En M. Ros, \& V. Gouveia, Psicología Social de los Valores Humanos (págs. 53-76). Madrid: Biblioteca Nueva.

Sora, B., Caballer, A., \& Peiró, J. M. (2014). La inseguridad laboral y sus consecuencias en un contexto de crisis económica. Papeles del Psicólogo, 35(1), 15-21.

Tedesco, J. C. (2008). Calidad de la educación y políticas educativas. Cuadernos de pesquisa, 39(138), 795-811.

Vandone, D. (2009). Consumer credit in Europe: Risks and opportunities of a dynamic industry. Springer Science \& Business Media. 
Vattimo, G. (2004). El fin de la modernidad. Nihilismo y hermenéutica en la cultura posmoderna. México: Gedisa.

Vergara, R. (2007). Tendencias demográficas y económicas en Chile y sus implicancias para la educación superior. Estudios públicos(106), 129-152.

Vozmediano, L., \& San Juan, C. (2010). Criminología Ambiental: ecología del delito y de la seguridad. Editorial UOC, 2011. Barcelona: OUC.

Wallerstein, I. (2005). Análisis de sistemas-mundo: una introducción. México: Siglo XXl.

World Bank. (2007). Doing Business in 2008. Washington DC: The World Bank.

Rodríguez Garcés, Carlos. Doctor por la Universidad de Barcelona, Docente en la Universidad del Bío-Bío, Director del Centro de Investigación CIDCIE, Chillán, Chile. ORCID: https://orcid.org/0000-0002-9346-0780. Líneas de investigación: Educación, Tecnologías de la Información, Familia. Correo: carlosro@ubiobio.cl, fono 56-422-463618. Casilla 447, Chillán, Chile.

Geraldo Padilla Fuentes. Trabajador Social, Licenciado en Trabajo Social. Universidad del Bío-Bío. Investigador Adscrito al Centro de Investigación CIDCIE, Universidad del Bío-Bío, Chillán, Chile. ORCID: https://orcid.org/0000-0003-0882-1818. Líneas de investigación: Educación y Sociedad. Correo: gpadilla@ubiobio.cl, fono 56-422-463616. Casilla 447, Chillán, Chile.

Javier Ávila Bascuñán, Licenciado en Trabajo Social. Universidad del Bío- Bío. Investigador ayudante Centro de Investigación CIDCIE. Universidad del Bío-Bío, Chillán, Chile. Líneas de investigación: Educación y Sociedad. Correo: javier.avila1501@alumnos.ubiobio.cl... fono 56422-463616. Casilla 447, Chillán, Chile. 